\title{
DISSOCIATIVE SYMPTOMATOLGY ON PTSD: A CLINICAL CASE
}

\author{
Sara González-Simarro' \\ 'Psicóloga Interna Residente del Hospital Santa Creu i Sant Pau, Barcelona,Spain.
}

Objectives:

Evaluate the extend of dissociative symptomatology in a chronic PTSD clinical case. Emphasize the need of exploring the dissociative dimension and, if appropriate, treating it specifically.

\section{Background:}

The relationship between dissociation and trauma is well stablished. Even more, a continuum has been described according to its severity: PTSD - complex PTSD - DID. Despite this, dissociative symptomatology has been widely neglected in PTSD literature, considered mostly as a peripheral feature. Recently however, the contributions on this field have promote a change of perspective.

Proof of that comes from DSM-5, as now includes a cluster of dissociative symptoms among PTSD criteria and allows the specification of a dissociative subtype of PTSD. Therefore, it appears essential to assess this symptomatology dimension and consider the necessity of treatment specifications.

\section{Materials and methods:}

Clinical case of a caucasian male aged 40 with a military history recently diagnosed with chronic PTSD.The measures included diagnostic interviews and assessment of symptoms severity as well as an evaluation of dissociative experiences.

- EGS-R (Posttraumatic Stress Disorder Symptom Severity Scale-R, Echeburúa et al., 2016).

- DES-II (Dissociative Experiences Scale-II, Bernstein Carlson \& Putnam, 1993).

\section{Results:}

\begin{tabular}{|l|c|}
\hline ECS-R & \\
\hline Intrusion symptoms & $14 / 15$ \\
\hline Avoidance & $8 / 9$ \\
\hline Negative alterations in cognitions and mood & $16 / 21$ \\
\hline Alterations in arousal and reactivity & $16 / 18$ \\
\hline Global Severity & $\mathbf{5 4 / 6 3}$ \\
\hline - Functional impairment & $16 / 18$ \\
\hline - Dissociative symptoms & $11 / 12$ \\
\hline
\end{tabular}

\section{Conclusions:}

Dissociative symptomatology is a well established cluster in the diagnosis of PTSD, currently considered in the DSM-5. The literature shows that the presence of dissociative phenomena is associated with high PTSD severity. Moreover, studies have linked the presence of dissociation after trauma and the likelihood of developing chronic PTSD. Taking this results into account, seems

crucial the exhaustive assessment of the dissociative dimension in order to specifically address this symptomatology in the treatment of PTSD.

\section{References:}

Carlson, E.B.\& Putnam, F.W.(1993). An update on the Dissociative Experience Scale. Dissociation 6(I), 16-27.

Echeburúa, E., Amor, P.J., Sarasua, B., Zubizarreta, I, Holgado-Tello, F.P., \& Muñoz, J.M. (20I6). Escala de Gravedad de Síntomas Revisada (EGS-R) del Trastorno de Estrés Postraumático según el DSM-5: propiedades psicométricas. Terapia psicológica, 34(2), I I I-I 28.

Tsai, J.,Armour, C., Southwick, S.M., \& Pietrzak, R.H.(2015). Dissociative subtype of DSM-5 posttraumatic stress disorder in U.S. veterans. Journal of Psychiatric Research, 66-67, 67-74. doi: 10.1016/j.jpsychires.2015.04.017

Van der Hart, O., Nijenhuis, E.R.S., \& Steele, K. (2005). Dissociation:An insufficiently recognized major feature of complex postraumatic stress disorder. Journal of Traumatic Stress, 18(5), 413-423. doi: 10. 1002/jts. 20049 